\title{
Baseline indicators to achive Land Degradation Neutrality at the country level
}

\author{
Melisa LJUŠA - Hamid ČUSTOVIĆ \\ University of Sarajevo, Faculty of Agricultural and Food Sciences, Zmaja od Bosne 8, 71000 Sarajevo, BiH, \\ E-mail: melisa.ljusa@gmail.com
}

Keywords: Land Degradation Neutrality, indicators, land cover, land productivity, carbon

\section{Introduction}

Land Degradation Neutrality (LDN) has been defined by the Parties to the UNCCD Convention as: A state whereby the amount and quality of land resources, necessary to support ecosystem functions and services and enhance food security, remains stable or increases within specified temporal and spatial scales and ecosystems (UNCCD, 2018). Having recognized the importance of the LDN process, Bosnia and Herzegovina $(\mathrm{BiH})$ voiced its interest in participating in the LDN process. The LDN baseline was defined based on a set of indicators: CORINE land cover/land use data, land productivity dynamics and soil organic carbon.

\section{Materials and methods}

In order to start with the process, LDN Working Group was established composed of representatives from the federal and cantonal level institutions, local communities, NGOs, universities, international organizations. Data from the CORINE database for the years 2000, 2006 and 2012 were used to analyze the land cover and land cover change. The data on land productivity (LPD) obtained and prepared by the Ispra Joint Research Center (2014) were used. The LPD data set was derived based on a 15-year series of data (19992013) of global NDVI observations at 10-day intervals and space resolution of $1 \mathrm{~km}$. The LPD data have five qualitative categories that describe land productivity trends. These qualitative categories do not correspond directly to quantitative measurements of losses or gains in the productivity of biomass, the correlation is indirect. The content of organic carbon (SOC) at depths of up to $30 \mathrm{~cm}$, the $250 \mathrm{~m}$ grid prepared by ISRIC.

\section{Results and discussion}

In the post-war period $\mathrm{BiH}$ has faced numerous social, economic and environmental problems among which the land degradation stands out as one of the most crucial ones (NAP, 2014).

In the Federation of $\mathrm{BiH}$, land cover changes were identified at 871 locations, i.e. polygons, on a total area of 33,976 ha in the period 2000-2006. The pressure on the land cover was considerably lower in the period 2006-2012, so that changes are visible on a total area of 10,991 ha (271 polygons). Data show that the collective category of Artificial areas was increased by 6,401 ha in the period 2000-2012. Croplands was decreased by 6,347 ha, mainly on account of the increase in Artificial areas. Forest areas were reduced by 17,962 ha. Approximately $85 \%$ of the total decrease is related to deforestation, while about $12 \%$ of decrease in forest land was caused by wild fires. Forest was also increased by 10,898 ha. This is mainly due to the gradual transition of agricultural land, pastures and abandoned areas resulting from the displacement of the population due to war activities and general 
abandonment of rural areas, into the succession of forest vegetation and ultimately into the forests.

The analysis shows that in the Federation of $\mathrm{BiH}$ reduction of productivity was identified on 11,400 ha, while early signs of reduction were observed on 13,800 ha. A total area of land that is stable but under stress, from the productivity viewpoint, amounts to 410,500 ha. Stable productivity without stress was identified on an area of 410,500 ha. Early signs of reduction and stable productivity, though under stress, can be classified as degraded areas and these cover most of the agricultural land. „Both climate change and land degradation can lead to a reduction in biomass and vegetation cover" (Reed and Stringer, 2016) The increase in productivity was identified on 2,066,400 ha. Land productivity increase is very pronounced. The reason for this lies in the fact that the largest part of the Federation of $\mathrm{BiH}$ is under forests, as well as that large area of agricultural land and pastures have been neglected for many years.

According to ISRIC data, the carbon content ranged between 0 to $174 \mathrm{t} / \mathrm{ha}$, while the average is $111,7 \mathrm{t} / \mathrm{ha}$. Carbon stocks in forest areas amount to $119.3 \mathrm{t} / \mathrm{ha}$, and in agricultural $107.9 \mathrm{t} / \mathrm{ha}$. The average level of carbon stocks in wetlands and water bodies is $98.3 \mathrm{t} / \mathrm{ha}$. The category with carbon stocks amounting 50-110 t/ha represents the soils of medium structure stability, fertility and water retention capacity. This category is predominant in the areas where agricultural production is the most intense. The category with carbon stock ranging 110-174 t/ha represents the soils of stable structure, fertility and water retention capacity. However, such a simplified classification is not entirely suitable for $\mathrm{BiH}$. The inner karst of the Dinarides gives the wrong picture of the situation as substantiated by the example provided below, since there is no way of identifying the accurate depth or skeletness.

\section{Conclusions}

The LDN process in the Federation of $\mathrm{BiH}$ has opened a number of issues that need to be resolved. The LDN baseline was defined based on a set of indicators. One of the disadvantages of these sets of data is their incoherence, for example, changes in space do not adequately reflect changes in productivity or in carbon. There is evident need for developing of land productivity and soil organic carbon indicators, especially carbon based on existing data for what strengthening of capacity would be needed. The achievement of the defined targets and measures of LDN, in addition to political will, requires legislation, financial sources, creation of public awareness and education about land and its functions within the ecosystem in general.

\section{References}

Čustović H., Ljuša M. (2018): Bosnia and Herzegovina, Federation of Bosnia and Herzegovina: Final report of the LDN Target Setting Programme.

UNEP, 2014: Action programme to combat land degradation and mitigate the effects of drought in $\mathrm{BiH}$.

UNCCD (2018): https://www.unccd.int/actions/achieving-land-degradation-neutrality

Mark S. Reed and Lindsay C. Stringer (2016): Land degradation, Desertification and Climate Change. Routledge, New York. 